\title{
HISTORIA DEL CATOLICISMO EN LA ARGENTINA ENTRE EL SIGLO XIX Y EL XX
}

\author{
Miranda Lida
}

Siglo XXI Editores, Buenos Aires, 2015.

272 páginas. ISBN 978-987-629-595-6

\section{Eliana Bertero}

El libro que nos convoca se inscribe en el campo de indagación de las relaciones entre la Iglesia Católica, la sociedad y la política. Se trata de una investigación documentada y minuciosa de la historia del catolicismo en la Argentina entre el Concilio Vaticano I, en 1870, y las vísperas del Concilio Vaticano II en 1962. Este recorrido entre dos siglos da cuenta del modo en que se fue conformando históricamente la relación entre la Iglesia Católica y la sociedad argentina, así como las implicancias políticas derivadas de ello. Una premisa de este trabajo es, en palabras de la autora, "sacar la historia del catolicismo de la endogamia historiográfica en la que se suele recaer y abordarla desde una perspectiva que trascienda el universo propio de los hombres de fe" (p. 13). Es por ello que en la introducción pone en discusión la pertinencia del concepto de secularización para el estudio de la historia del catolicismo. Al mismo tiempo, revisa la imagen construida fuertemente por una historiografía rupturista, que enfatiza el contraste absoluto entre el pasado secularizador y liberal del siglo XIX con el renacimiento cristiano de la década de 1930. Esta obra sugiere nuevas lecturas de la historia del catolicismo, que permiten repensar la relación con el proceso de modernización finisecular y con la expansión de la sociedad de masas en el siglo $X X$. En este sentido, la escritura destaca las estrategias que despliega la Iglesia para, en la medida de lo posible, acompañar el paso de las transformaciones de su tiempo, poniendo de relieve las tensiones y claroscuros de este proceso. 
Se estructura a partir de una introducción, nueve capítulos y un epílogo. El primer capítulo está dedicado a explicitar los cambios producidos en la Iglesia Católica durante el proceso de consolidación del Estado y la modernización del '80. La autora sostiene que este proceso le permitió a la Iglesia construirse institucionalmente, afianzando su presencia a nivel territorial, producto de la consolidación del Estado, de las transformaciones socioeconómicas y del desarrollo de la red de transportes. Si bien destaca las fricciones con un Estado que impone las leyes laicas, esto no redundaría en un completo desplazamiento de la Iglesia de la sociedad argentina. De esta manera, afirma que "incluso el catolicismo podía ser funcional al proceso de modernización urbana, inculcando valores de urbanidad y buenas costumbres en una sociedad poco sedimentada" (p. 35). Según la autora, este rol del catolicismo fue admitido por las élites sociales y políticas, para quienes resultaba fundamental asimilar a los inmigrantes, creando cánones de decencia y respetabilidad en una sociedad aluvial.

Le sigue un capítulo en el cual se abordan las tensiones y transformaciones del catolicismo finisecular y la Argentina del centenario. Analiza los cambios en la estructura organizativa de la Iglesia y la inserción en el marco internacional de la jerarquía eclesiástica. En este contexto, se reconocen las iniciativas que tienden a la integración institucional y a la nacionalización del catolicismo. Entre las más novedosas, se ocupa de la Federación de Círculos Católicos de Obreros, que se crea en 1892 para atender la cuestión social en plena crisis económica. Sin embargo, la autora advierte que a pesar de estos intentos por conformar un movimiento integrado y homogéneo, la primera década del siglo XX encuentra al catolicismo segmentado por la cuestión social y las diferencias de clase, el género, el idioma y en menor medida, los regionalismos. "De ahí que buscara la manera de entroncarse con la idea de nación, con la cual confiaba superar algunas de estas fisuras" (p. 57).

En el tercer capítulo se examinan las diversas estrategias desplegadas por la Iglesia para encauzar los desafíos presentados por la ampliación del sufragio y la democracia política, así como también por la democratización social y cultural. Se presenta un período en el cual la Iglesia se abocó a la búsqueda de la integración institucional, impulsando la nacionalización del laicado a través de la consolidación de los círculos obreros y la creación de nuevas organizaciones de alcance nacional. En esta línea de análisis, aborda la celebración 
del Congreso Eucarístico Nacional celebrado en 1916, y la experiencia de la Gran Colecta Nacional, en 1919. En síntesis, la autora plantea que a través de diversos mecanismos la Iglesia se propuso influir políticamente e intervenir en la cuestión social, problema que ocupó un lugar predominante durante la crisis de posguerra. Asimismo, a través del relato es posible reconocer las dimensiones del activismo católico previo a 1930.

Los dos capítulos siguientes examinan, en un sentido amplio, los modos en que el catolicismo se propuso intervenir en los debates culturales de una época en la cual primaba la necesidad de poner límites a la libertad de expresión y a la expansión de las industrias culturales, como el teatro y el cine. La autora aborda el abanico de recursos y estrategias por medio del cual la Iglesia pretendió contener los desbordes "inmorales" de la sociedad de masas apelando, por ejemplo, a la calificación sistemática y a la difusión de listados de películas aceptables. También, apostando a la propia contraoferta de libros, películas, teatro y radio moralmente "sanos", despojados de pornografía, para la familia. En este contexto, analiza el crecimiento expansivo de la prensa católica, en su mayoría de corte puramente militante. En tanto producto de este crecimiento, un capítulo aparte refiere a la revista Criterio. A diferencia del resto de la prensa militante, la publicación apuntaba a instalar un espacio católico de prestigio intelectual y a convertirse en una voz capaz de intervenir en los debates públicos. En este sentido, pone de relieve cómo en la década de 1930, la revista estuvo jalonada por los debates políticos en torno de los totalitarismos y del rechazo al comunismo, en la medida en que abrió las puertas a las plumas más recalcitrantes del catolicismo, como Julio Meinvielle.

A través de este recorrido, la autora reconstruye una imagen de los años 20 descentrada de aquellos enfoques rupturistas que la observan como antesala de la década de 1930. En esta dirección sostiene que "los años veinte dieron por saldo múltiples catolicismos, que variaban en función no sólo de la pertenencia social de sus destinatarios (género, clase social, origen inmigratorio), sino además de consideraciones culturales. El problema que la década sacó a la luz con contundencia era la enorme brecha que existía entre el catolicismo culto y el popular, que corría riesgo de convertirse en un abismo insondable" (p.116).

La década de 1930 y la compleja relación entre catolicismo y el peronismo, se tratan en los siguientes capítulos. Suele caracterizarse a este período 
como una época de neta avanzada clerical tanto en el plano social como político, producto de la crisis del liberalismo. Este proceso es observado en el fortalecimiento del entramado institucional de la Iglesia y en la imagen de un movimiento compacto, casi monolítico articulado por el integrismo católico. Su influencia política puede advertirse en los estrechos vínculos que tejió la jerarquía eclesiástica con las fuerzas armadas, según demostró el historiador Loris Zanatta en el nacimiento del "mito de la nación católica". Sin embargo, el relato que realiza la autora, pone en discusión esta lectura monolítica del pasado. Así, la década del treinta se revela tanto más compleja y densa de lo que parece a primera vista. Desde la perspectiva de la historia social, atenta al modo en que los discursos circulan y se reciben socialmente, Miranda Lida comprende e interpreta las intervenciones públicas de la Iglesia, sus tradiciones ideológicas y sus reivindicaciones en el plano político e incluso estatal.

Desde este enfoque, pone de manifiesto los aspectos centrales del proceso homogeneización, destacando el rol de la Acción Católica y el fortalecimiento de la jerarquía eclesiástica. Aborda el Congreso Eucarístico Internacional, no sólo como una movilización católica de masas, sino como un fenómeno social y cultural que excede el marco político y religioso. Para dar cuenta de ello, expresa la dimensión turística del evento, en la medida en que los peregrinos provenientes del interior del país visitaron sitios turísticos, tiendas comerciales y grandes ciudades cercanas a la capital. Para muchos de los participantes fue un evento social, cultural y turístico complejo que desbordaba por completo la esfera religiosa.

En cuanto a las transformaciones socioeconómicas operadas desde la crisis del '30, la autora analiza cómo el catolicismo redefine el sentido de la acción social cristiana. Advierte que comienza a abordarse ya no como mera caridad, sino en términos de justicia social. Da cuenta de un proceso complejo por medio del cual los discursos y prácticas tradicionales como las colectas y campañas de caridad dejan paso a "la aceptación del papel del estado como árbitro de la conflictividad social y obrera, con el cual incluso los católicos se prestaron ampliamente a colaborar" (p. 164). Destaca la creciente presencia de grupos católicos de composición obrera, especialmente de las ramas juveniles como las Vanguardias Obreras Católicas y la Juventud Obrera Católica, que desde mediados de la década de 1940 fueron interpelados por el peronismo. 
El capítulo ocho se ocupa del catolicismo en la coyuntura peronista y de los cambios socioculturales de posguerra. La relación con el peronismo se presenta compleja, cargada de contradicciones y ambivalencias. Por un lado, la justicia social constituía un terreno común que los identificaba, aunque el catolicismo tenía una lectura moderada de la cuestión, en sintonía con la Rerum Novarum y la doctrina social de la Iglesia. Por el otro, había aspectos conflictivos que alejaban a muchos católicos del peronismo. Algunos lo observaban con desconfianza por su ataque a los sectores patronales y el desafío que planteaba al capital, así como por el espíritu carnavalesco que nutría a las movilizaciones populares, difícil de conciliar con el orden y la rigidez de las fiestas católicas más tradicionales. Otros, como las ramas juveniles obreras, se vieron interpeladas y atraídas, cuestión que se puso de manifiesto en las movilizaciones religiosas que adquirieron un tinte diferente, cargadas de consignas, lenguajes y rituales que resultaban más cercanos a los del peronismo. Estas contradicciones y ambivalencias convergen y se politizan a la luz del conflicto entre el gobierno peronista y la Iglesia Católica.

Finalmente, se analizan las vicisitudes y transformaciones del catolicismo argentino en un contexto de cambios a escala internacional y regional, caracterizado por la creciente integración de los episcopados latinoamericanos a partir de la creación en 1955 del Consejo Episcopal Latinoamericano (CELAM). En este marco, reconstruye el conflicto con el peronismo y el comportamiento de la Iglesia como un factor de poder. Miranda Lida identifica los cambios en las prácticas culturales y asociativas del movimiento laical, como la popularización de los campamentos juveniles de verano, las misiones rurales o en villas miseria, las peñas folclóricas desarrolladas en sedes parroquiales, que provocaron una profunda modificación en la imagen tradicional de la Iglesia, solemne, ceremoniosa y rígida. En el epílogo advierte que el Concilio Vaticano II, lejos de introducir cambios radicales, vendría a condensar, fortalecer y encauzar estas tendencias, que en plena década de 1960, vinieron a aggiornar las facetas más anquilosadas de la institución. Coincidiendo con las palabras de Luis Alberto Romero, la autora presenta un relato sugestivo y original del mundo católico, la Iglesia y sus laicos, y de su lugar en un período de la historia argentina signado por la democratización y las batallas culturales e ideológicas. Al proponer una historia social y política del catolicismo, este libro aporta una mirada de conjunto, completa y compleja, de la relación entre la Iglesia Católica y la sociedad argentina. 